BMJ Open

Diabetes

Research

\& Care

\title{
Development and validation of an instrument to measure collaborative goal setting in the care of patients with diabetes
}

\author{
Heather L Morris, ${ }^{1}$ Levent Dumenci, ${ }^{2}$ Jennifer E Lafata ${ }^{2}$
}

To cite: Morris HL, Dumenci L, Lafata JE. Development and validation of an instrument to measure collaborative goal setting in the care of patients with diabetes. BMJ Open Diabetes Research and Care 2017;5: e000269. doi:10.1136/ bmjdrc-2016-000269

Received 11 May 2016 Accepted 6 October 2016

\section{CrossMark}

\footnotetext{
${ }^{1}$ Department of Health Outcomes and Policy, University of Florida, Gainesville, Florida, USA ${ }^{2}$ Virginia Commonwealth University, Richmond, Virginia, USA
}

Correspondence to Dr Heather L Morris; hlmorris27@ufl.edu

\section{ABSTRACT}

Objective: Despite known benefits of patientperceived collaborative goal setting, we have a limited ability to monitor this process in practice. We developed the Patient Measure of Collaborative Goal Setting (PM-CGS) to evaluate the use of collaborative goal setting from the patient's perspective.

Research design and methods: A random sample of 400 patients aged 40 years or older, receiving diabetes care from the Virginia Commonwealth University Health System between 8/2012 and 8/2013, were mailed a survey containing potential PM-CGS items $(n=44)$ as well as measures of patient demographics, perceived self-management competence, trust in their physician, and selfmanagement behaviors. Confirmatory factor analysis was used to evaluate construct validity. External validity was evaluated via a structural equation model (SEM) that tested the association of the PM-CGS with self-management behaviors. The direct and two mediated (via trust and self-efficacy) pathways were tested.

Results: A total of 259 patients responded to the survey (64\% response rate), of which 192 were eligible for inclusion. Results from the factor analysis supported a 37-item measure of patient-perceived CGS spanning five domains: listen and learn; share ideas; caring relationship; measurable objective; and goal achievement support $(\chi=4366.13, p<0.001$; RMSEA $=0.08$ ). Results from the SEM supported the external validity of the PM-CGS. The relationship between CGS and self-management was partially mediated by perceived competence $(p<0.05)$. The direct effect between the PM-CGS and selfmanagement was significant $(p<0.001)$.

Conclusions: CGS can be validly measured by the 37-item PM-CGS. Use of the PM-CGS can help illustrate actionable deficits in goal-setting discussions.

\section{INTRODUCTION}

Previous studies have found that patient reports of collaborative goal setting with healthcare providers are associated with increased perceived self-management competence $^{1-3}$ and trust in their physician. ${ }^{1}{ }^{4}$

\section{Key messages}

- Patient reports of collaborative goal setting have been linked to increased self-management and trust in the physician.

- This study produced a valid measure of collaborative goal setting.

- This measure can help highlight actionable deficits in goal-setting discussions.

Patient reports of engaging in collaborative goal setting have also been found to be associated with improved self-management behaviors and health outcomes, including improvements in Hemoglobin ( $\mathrm{Hb}) \mathrm{A} 1 \mathrm{c}$ and blood pressure levels among patients with diabetes and hypertension. ${ }^{15-7}$ However, despite recommendations for its use $^{8-9}$ and the growing evidence of its benefits, we continue to have a limited understanding of how to measure and foster this process in practice.

Heisler et a $\bar{\varphi}$ hypothesized that collaborative goal setting is a process that involves five domains: (1) sharing responsibility for making decisions, (2) mutually agreeing on the goal, (3) discussing self-care management options, with the patient, (4) sharing beliefs about illness treatment, and (5) information about their life and values. ${ }^{5}$ To the best of our knowledge, no study has empirically tested the conceptualization put forth by Heisler. $^{5}$ Moreover, studies that have shown associations between patient-reported engagement in collaborative goal setting and improved outcomes have not enabled an understanding of the specific processes necessary for patients to acknowledge their participation in a collaborative goal-setting process. Instead, these prior studies have each relied on the Patient Assessment of Chronic Illness Care (PACIC), an instrument that leaves the definition of collaborative goal setting open to the respondents' individual interpretations. ${ }^{1} 610$ 
We have previously used qualitative research methods to identify what needs to occur for a goal-setting process to be considered collaborative in the eyes of patients with diabetes. ${ }^{11}$ Findings from that study indicated that patients conceptualize collaborative goal setting as a multidimensional process that unfolds over time within the context of a caring relationship with their clinician. ${ }^{11}$ Similar to how Heisler $e t a \check{l}$ conceptualized the process, patients identified multiple domains of collaborative goal-setting discussions: (1) the patient and physician listen and learn from each other, (2) the patient and physician share ideas, (3) the patient and physician agree on a measurable objective, and (4) the physician provides support for goal achievement.

The primary objective of this study was to use results from our prior formative study to develop a patientreported measure of collaborative goal setting that could be used for monitoring and evaluating the occurrence of collaborative goal setting among patients with diabetes. We report findings from analyses testing the internal and external validity of the Patient Measure of Collaborative Goal Setting (PM-CGS) measure. The latter was done by using the previously hypothesized pathways through which engagement in collaborative goal setting is thought to impact self-management behaviors. $^{1-4}$

\section{RESEARCH DESIGN AND METHODS}

\section{Sample}

Study eligible participants were those patients receiving care for their diabetes from the Virginia Commonwealth University Health System (VCU-HS). Eligible patients were aged 40 years or older with an outpatient visit to a primary care or endocrinology for diabetes (ie, ICD-9=250 or 366.41, 357.2, 362.0) between August 2012 and August 2013. Patients <40 years of age and those with gestational diabetes were excluded. Individuals who had previously participated in a focus group in support of our formative work ${ }^{11}$ were also excluded. Patients were identified using the structured data contained within the electronic health record at VCU-HS. From among the over 18000 patients identified, we used random sampling methods to select $\mathrm{N}=400$ patients for study inclusion. This was achieved using the SPSS V.21 random number generator.

\section{Initial measure development}

Initial measure development was divided into two consecutive phases. In the first phase, we developed survey items for potential inclusion in the PM-CGS based on results from our formative research. Thus, while Heisler's conceptualization of collaborative goal setting was considered, items developed were based primarily on findings from a previously conducted qualitative study in which we used focus groups to explore patient perceptions of collaborative goal setting in diabetes care. ${ }^{11}$ That study resulted in a conceptualization of collaborative goal setting as including five domains: (1) listen and learn from each other (ie, patients and physicians listen and learn from each other), (2) share ideas (ie, the physician shares his or her ideas and gives the patient the opportunity to share), (3) the context of a caring relationship (ie, physicians have a good bedside manner, are compassionate and sensitive to patient needs), (4) agree on a measurable objective (ie, patients agree on a measureable objective with their physician), and (5) support for goal achievement (ie, the provision of support by the physician in a number of forms: emotional, tangible, or instrumental). ${ }^{11}$ For each of these domains we developed 6-11 survey items with a 5-point Likert-type response format ranging from 1 (strongly disagree) to 5 (strongly agree). In total, 77 items were originally developed.

In the second phase, the initial pool of 77 items was revised and refined by incorporating input from an expert panel and by conducting cognitive interviews. The expert panel included a psychometrician, a primary care physician, a health communication specialist, and a health psychologist. Input from the expert panel was used to revise question wording and eliminate redundant items $(n=10)$. The remaining 67 items were tested via patient cognitive interviews. Cognitive interviews used the 'concurrent think aloud' method ${ }^{12} 13$ and were conducted among a convenient subsample of original focus group participants from our qualitative study of two males (one black and one white) and two females (one black and one white). These interviews were used to pilot test the items for comprehensibility and relevance, and to ensure items reflected themes identified from the focus groups. Participants were asked to provide their thoughts as they completed the questionnaire and responses were probed for further insight. ${ }^{13}$ Cognitive interviews took on average 30 mins to complete (range: 25-40). Based on feedback from the cognitive interviews, the initial pool of items was further reduced resulting in a total of 44 items for further consideration in the PM-CGS.

\section{Survey administration}

A letter of study introduction and the survey were mailed to patients in October 2013. The letter of study introduction described the study in general terms, asked that the patient complete the enclosed questionnaire, and included a $\$ 2.00$ bill. Survey administration followed a Dillman approach: ${ }^{14}$ two weeks after the initial mailing, non-respondents received a reminder postcard; after an additional 2 weeks, non-respondents were sent another survey packet. Correspondence was mailed using first class postage, personalized communication, and stamped return envelopes, each of which has been shown to improve response rates. ${ }^{15}{ }^{16}$ Patients who returned a survey received a $\$ 20$ gift card to a local retail store. Data entry for returned surveys was achieved with optical mark recognition using Remark OMR. To be included in the current analyzes, the survey 
respondent had to report engaging in a health-related goal discussion in the previous 6 months with a healthcare provider.

\section{Measures}

The questionnaire included the PM-CGS items, as well as the following previously validated measures: the Perceived Competence Scale, ${ }^{17}$ the Trust in Physician Scale, ${ }^{18}$ and the Summary of Diabetes Self-Care Activities (SDSCA) measure. ${ }^{19}$ The survey also included items specific to the patient's socio-demographic characteristics including age, race, gender, marital status, employment status, income, and level of education achieved. The collaborative goal setting and selfmanagement measures were treated as latent variables, each comprising five domains.

\section{Patient perceptions of collaborative goal setting}

The PM-CGS items were designed to measure the extent to which patients report engaging in collaborative goal setting with their healthcare provider/provider team over the past 6 months. Measure responses depicted participation in collaborative goal setting within five domains: (1) listen and learn from each other, (2) share ideas, (3) caring relationship, (4) agree on a measurable objective, and (5) support for goal achievement. For each domain, there were between five and nine survey items for which respondents were asked to express the degree to which they agree with the statement using a 5-point scale ranging from strongly disagree (1) to strongly agree (5) with higher scores representing patient reports of relatively more collaborative goal setting. A summary score across all domains provided an overall assessment of the PM-CGS where higher scores also represented patient reports of more collaborative goal setting.

\section{Statistical methods}

Confirmatory factor analysis with full information maximum likelihood estimation ${ }^{20}$ was used to test the internal validity (ie, measurement model) of the instrument. Prior to conducting the confirmatory factor analysis, survey data were evaluated for missing data. No item was found to be missing more than $5 \%$.

Consistent with our conceptual model of collaborative goal setting, we tested a second-order factor model. This model used a multidimensional representation of collaborative goal setting where the five first-order factors were represented by the five conceptual domains of collaborative goal setting as previously identified: (1) listen and learn from each other, (2) share ideas, (3) caring relationship, (4) agree on a measurable objective, and (5) support goal achievement. Collaborative goal setting was represented as a second-order factor. Mplus V.6 was used to estimate the model. $\mathrm{Hu}$ and Bentler ${ }^{21}$ criteria were used to evaluate model fit. ${ }^{21}$ Items with standardized factor loadings $<0.40$ were removed prior to final model estimation.

Structural equation modeling (SEM) was used to test the external validity of the final measure. This was done by testing the pathways through which collaborative goal setting impacts self-management behaviors. Collaborative goal setting and self-management variables are specified as latent variables in the SEM (figure 1) where each latent variable is comprised of five domains and the items that collectively represent the respective domains. As depicted in figure 1, perceived competence and trust were used as observed variables mediating the relationship between collaborative goal setting and selfmanagement. The model was tested with and without the presence of covariates.

\section{RESULTS}

\section{Sample characteristics}

A total of 259 individuals returned the survey $(64 \%$ response rate). Of those, 20 individuals were excluded ( $n=19$ did not report having diabetes and $n=1$ reported having gestational diabetes). Among the remaining 239 individuals, n=192 reported discussing a health-related goal with their clinician in the past 6 months and were

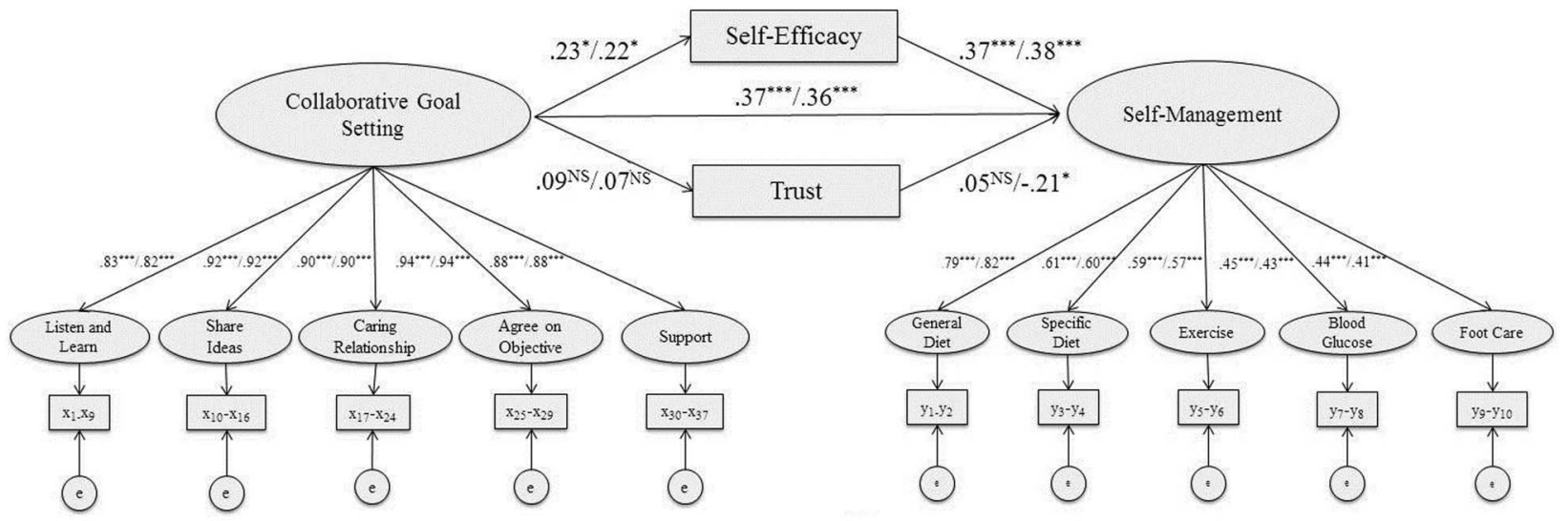

1. Depicted parameters are unadjusted/adjusted estimates

Figure 1 Unadjusted and adjusted structure equation model parameter estimates. 
included in the current analyses. Respondents were able to designate their goal topic from a list of five common goals. Of the 192 individuals, goal topics included: weight loss, exercise, healthier eating, smoking cessation, or better control of blood pressure, lipid levels, or HbA1c. The mean age of eligible survey respondents was 60.1 years $(\mathrm{SD}=9.36$; range $41-89) ; 71 \%$ were women and $67 \%$ were black (table 1 ). The majority had graduated from high school (69\%) and was insured (92\%). A total of $32 \%$ were married, and $45 \%$ had an annual income below $\$ 15000$.

On average, patients endorsed that the goal-setting process used with their clinician over the past 6 months was collaborative (mean $=4.47$, range 1 (strongly disagree) to 5 (strongly agree)). Participants were found to report high levels of trust in their physician (mean=85.02, $\mathrm{SD}=14.14$, range $33-100$ ), as well as high levels of perceived self-management competence (mean=5.80, $\mathrm{SD}=1.51)$. Patients reported engaging in each of the self-management behaviors most days of the week. On average, they reported engaging in general

\begin{tabular}{|c|c|}
\hline Age & $60.1(\mathrm{SD}=9.36)$ \\
\hline \multicolumn{2}{|l|}{ Gender } \\
\hline Male & $29 \%$ \\
\hline Female & $71 \%$ \\
\hline \multicolumn{2}{|l|}{ Education } \\
\hline Grades 1-8 & $9 \%$ \\
\hline Grade 9-11 & $22 \%$ \\
\hline High school graduate & $25 \%$ \\
\hline College $1-3$ years & $25 \%$ \\
\hline College graduate & $19 \%$ \\
\hline \multicolumn{2}{|l|}{ Marital status } \\
\hline Currently married & $32 \%$ \\
\hline Never married & $24 \%$ \\
\hline Separated & $9 \%$ \\
\hline Divorced & $22 \%$ \\
\hline Widowed & $13 \%$ \\
\hline \multicolumn{2}{|l|}{ Race } \\
\hline White & $27 \%$ \\
\hline Black & $67 \%$ \\
\hline White and American Indian & $6 \%$ \\
\hline Hispanic or latino & $3 \%$ \\
\hline Employed & $25 \%$ \\
\hline Insured & $92 \%$ \\
\hline \multicolumn{2}{|l|}{ Income } \\
\hline$\$ 0-\$ 14999$ & $45 \%$ \\
\hline$\$ 15000-\$ 74999$ & $42 \%$ \\
\hline$\$ 75000$ or more & $12 \%$ \\
\hline \multicolumn{2}{|l|}{ Self-reported health status } \\
\hline Excellent & $2 \%$ \\
\hline Very good & $17 \%$ \\
\hline Good & $38 \%$ \\
\hline Fair & $33 \%$ \\
\hline Poor & $10 \%$ \\
\hline Current smoker & $18 \%$ \\
\hline Depressive symptoms & $47 \%$ \\
\hline
\end{tabular}

diet self-management behaviors 4.91 days $(\mathrm{SD}=1.74)$, specific diet 4.22 days $(\mathrm{SD}=1.51)$, exercise 3.72 days $(\mathrm{SD}=2.23)$, blood sugar testing 5.04 days $(\mathrm{SD}=2.42)$, and foot care 4.37 days $(\mathrm{SD}=1.43)$ all with ranges from zero to seven.

\section{Internal validity}

Table 2 lists the 37 items included in the instrument. The overall fit of the model was good $\left(\chi^{2}=4366.13\right.$, $\mathrm{df}=666 ; \mathrm{p}<0.001 ; \mathrm{RMSEA}=0.07)$. Each of the items had significant $(p<0.001)$ loadings onto their respective domains. These first-order factors had loadings that ranged from 0.57 to 0.93 (mean=0.78; median=0.78) (table 2). Within the second-order factor model, where the construct of collaborative goal setting is represented by the five first-order factors, each factor is significantly $(\mathrm{p}<0.001)$ and strongly (range: $0.82-0.95$; mean $=0.90$; median $=0.90$ ) associated with the construct of collaborative goal setting (table 2). The internal consistency of each of the five domains was high (range: 0.894-0.940), as was the level of consistency for the second-order factor collaborative goal setting $(\alpha=0.927)$.

\section{External validity}

The overall fit of the unadjusted model was good $\left(\chi^{2}=4827.38, \mathrm{df}=820 ; \mathrm{p}<0.001 ; \mathrm{RMSEA}=0.07\right)$. Three of the pathways tested within the model were found to be statistically significant. Collaborative goal setting was significantly associated with increased perceived competence $(p<0.03)$ as well as with self-management behaviors $(p<0.001)$. Furthermore, perceived competence was significantly associated with self-management behaviors $(\mathrm{p}<0.001)$. Patient reports of physician trust were not related to either collaborative goal setting or self-management behaviors $(p>0.10)$. Standardized parameter estimates can be found in figure 1 .

In addition to testing the pathways of significance, a mediation model was also tested as increased reports of collaborative goal setting were shown to be significantly associated with increased perceived self-management competence, which was significantly associated with increased self-management behaviors. The mediation model that was tested, therefore, was whether the relationship between collaborative goal setting and selfmanagement was mediated by the patient's perceived competence. Results supported that the relationship between collaborative goal setting and self-management was partially mediated by perceived competence $(\mathrm{p}<0.05)$.

After controlling for patient socio-demographic characteristics, the partial mediation model with perceived competence was no longer statistically significant ( $p=0.055)$. However, the direct effects remained significant: collaborative goal setting and perceived competence were significantly associated with improved self-management $(p<0.001)$, and collaborative goal setting remained associated with improved perceived competence $(\mathrm{p}<0.05)$. In addition, a positive 
Table 2 Second-order factoral model: collaborative goal setting confirmatory factor analysis $(n=192)$

\begin{tabular}{|c|c|c|}
\hline First-order factors & Factor loadings & Mean (SD) \\
\hline Factor 1: Listen and learn from each other & 0.82 & $4.6(0.60)$ \\
\hline Item 1: I asked my doctor any questions I had & 0.77 & $4.6(0.77)$ \\
\hline Item 2: My doctor asked me if I had any concerns & 0.73 & $4.7(0.80)$ \\
\hline Item 3: My doctor explained the reasons for the goal & 0.77 & $4.7(0.63)$ \\
\hline Item 4: I learnt important things from my doctor & 0.70 & $4.6(0.79)$ \\
\hline Item 5: My doctor and I discussed the reasons for the goal & 0.80 & $4.6(0.79)$ \\
\hline Item 6: I listened to what my doctor had to say & 0.64 & $4.6(0.82)$ \\
\hline Item 7: I told my doctor important things about me & 0.61 & $4.6(0.76)$ \\
\hline Item 8: I told my doctor about any concerns I had & 0.63 & $4.5(0.95)$ \\
\hline Item 9: My doctor gave me the opportunity to ask any questions I had & 0.72 & $4.7(0.82)$ \\
\hline Factor 2: Share ideas & 0.91 & $4.4(0.80)$ \\
\hline Item 10: I made sure my doctor knew about things that were important to me & 0.66 & $4.4(1.03)$ \\
\hline Item 11: I told my doctor about important things in my life & 0.66 & $4.2(1.13)$ \\
\hline Item 12: My doctor shared his/her ideas with me & 0.80 & $4.4(1.02)$ \\
\hline Item 13: I was interested in my doctor's ideas & 0.73 & $4.5(0.92)$ \\
\hline Item 14: My doctor provided important medical information to me & 0.77 & $4.5(0.87)$ \\
\hline Item 15: I shared my ideas with my doctor & 0.77 & $4.4(0.90)$ \\
\hline Item 16: I felt confident my doctor understood what was important to me & 0.90 & $4.5(1.01)$ \\
\hline Factor 3: Caring relationship & 0.90 & $4.6(0.60)$ \\
\hline Item 17: My doctor treated me as a person & 0.78 & $4.8(0.72)$ \\
\hline Item 18: I respected my doctor's opinions & 0.93 & $4.7(0.69)$ \\
\hline Item 19: My doctor showed he/she cared about me as a person & 0.93 & $4.6(0.74)$ \\
\hline Item 20: My doctor respected my opinion & 0.83 & $4.6(0.79)$ \\
\hline Item 21: My doctor was honest with me & 0.90 & $4.7(0.68)$ \\
\hline Item 22: My doctor spent enough time with me & 0.81 & $4.5(0.87)$ \\
\hline Item 23: I showed my doctor that I cared about achieving the goal & 0.74 & $4.5(0.86)$ \\
\hline Item 24: I was honest with my doctor & 0.72 & $4.7(0.71)$ \\
\hline Factor 4: Agree on a measurable objective & 0.95 & $4.4(0.79)$ \\
\hline Item 25: I felt good about the goal & 0.79 & $4.3(0.94)$ \\
\hline Item 26: My doctor helped me understand what the specific goal is & 0.84 & $4.5(0.82)$ \\
\hline Item 27: I had confidence that I could achieve the goal & 0.72 & $4.2(1.05)$ \\
\hline Item 28: My doctor and I agreed on the specific goal that was set & 0.82 & $4.4(0.94)$ \\
\hline Item 29: My doctor and I discussed the potential specifics of the goal & 0.79 & $4.4(0.93)$ \\
\hline Factor 5: Support for goal achievement & 0.90 & $4.3(0.87)$ \\
\hline Item 30: My doctor gave me information I could take home about the goal & 0.57 & $4.3(1.14)$ \\
\hline Item 31: I told my doctor I felt like I could achieve the goal & 0.78 & $4.3(0.93)$ \\
\hline Item 32: My doctor and I discussed strategies for achieving the goal & 0.89 & $4.2(1.06)$ \\
\hline Item 33: I was comfortable discussing any challenges I might have achieving the goal & 0.74 & $4.4(0.93)$ \\
\hline Item 34: My doctor made me feel like I could achieve the goal & 0.88 & $4.4(0.94)$ \\
\hline Item 35: My doctor and I came up with a strategy for how to achieve the goal & 0.90 & $4.2(1.15)$ \\
\hline Item 36: My doctor checked to make sure I understood the goal & 0.88 & $4.3(1.08)$ \\
\hline Item 37: My doctor described how to achieve the goal & 0.90 & $4.3(1.03)$ \\
\hline
\end{tabular}

Note: All factor loadings are significant $(\mathrm{p}<0.001)$. Standardized parameter estimates are shown. All second-order factor loadings are in bold.

The second-order factor has Cronbach's $\alpha$ of 0.927 .

relationship between collaborative goal setting and a patient's trust in their physician also became statistically significant $(\mathrm{p}<0.05)$.

Covariate effects are shown in table 3. Older patients were more likely to report engaging in collaborative goal setting, have a high level of perceived competence, and were more likely to report trust in the physician. Black patients were less likely than whites to report engaging in collaborative goal setting. Compared with patients with a college degree, patients with a high school degree were less likely to report engaging in collaborative goal setting. Finally, patients with lower levels of education were less likely to have a high level of trust in their physician and to report engaging in self-management behaviors.

\section{CONCLUSIONS}

Among a sample of patients receiving outpatient care for their diabetes, a multidimensional measure of collaborative goal setting was created. Consistent with an a priori conceptualization of collaborative goal setting, ${ }^{11}$ as well as other previous depictions, ${ }^{5}$ the measure consisted of items that span five domains: (1) listen and learn from each other, (2) share ideas, (3) caring 
Table 3 Regression coefficients of constructs from the adjusted structural equation model

\begin{tabular}{|c|c|c|c|c|}
\hline & $\begin{array}{l}\text { Collaborative goal } \\
\text { setting outcome }\end{array}$ & $\begin{array}{l}\text { Perceived competence } \\
\text { outcome }\end{array}$ & $\begin{array}{l}\text { Trust in physician } \\
\text { outcome }\end{array}$ & $\begin{array}{l}\text { Self-management } \\
\text { outcome }\end{array}$ \\
\hline \multicolumn{5}{|c|}{ Socio-demographics as predictors } \\
\hline Age & 0.06 & $0.18^{\star \star}$ & 0.01 & 0.00 \\
\hline \multicolumn{5}{|l|}{ Race } \\
\hline Black & -0.01 & -0.14 & 0.14 & 0.14 \\
\hline Other & 0.08 & $-0.15^{\star}$ & -0.12 & 0.05 \\
\hline \multicolumn{5}{|l|}{ Education } \\
\hline Less than & 0.12 & 0.08 & -0.11 & -0.03 \\
\hline \multicolumn{5}{|l|}{ HS } \\
\hline HS degree & -0.03 & -0.11 & -0.09 & $-0.20^{\star *}$ \\
\hline
\end{tabular}

relationship, (4) agree on a measureable objective, and (5) support for goal achievement. The PM-CGS measure is reliable and its external validity was supported among patients with diabetes. Collaborative goal setting, as measured by the PM-CGS, was positively and substantively associated with improved self-management behaviors. In addition, we found collaborative goal setting, as measured by the PM-CGS, might be associated with improved self-management behaviors by improving patients' perceived competence for those behaviors. Furthermore, once patient socio-demographic characteristics were controlled, patient reports of collaborative goal setting as reported by the PM-CGS were also associated with improved physician trust, a patient-provider relationship characteristic known to be associated with improved health outcomes.

The PM-CGS was designed to ascertain the extent to which a collaborative goal-setting process occurred between a patient and their clinician team. As such, the PM-CGS builds on the initial conceptualization of collaborative goal setting put forth by Heisler, ${ }^{5}$ and brings forth the patients' voice to the conceptualization by focusing on those domains previously identified in a qualitative study as important to patients' consideration of collaborative goal setting. Consistent with Heisler, ${ }^{5}$ the conceptualization of collaborative goal-setting process tested here depicts collaborative goal setting as a communication process in which patients and their clinicians share ideas and information, and reach agreement on a goal or target level. However, our prior qualitative findings ${ }^{11}$ led us to test the appropriateness of adding that these interactions needed to occur within the context of a caring relationship with the clinician, and that they required ongoing support for a goal to be achieved. Results support the appropriateness of including both these domains, as they were associated with the overall collaborative goal-setting construct. The PM-CGS assesses the components of collaborative goal setting, including the patient's and the healthcare providers' responsibilities that patients endorse as important to collaborative goal setting. As the focus of this measure is the patient's perception of the extent to which the interaction that transpires between them and clinicians reflected a collaborative goal- setting process, factors such as goal quality or other goal characteristics is not considered.

As a result of this research, a tool now exists that can appropriately and accurately measure collaborative goal setting. With such a measure in hand, we can use patient reports to identify when collaborative goal setting has occurred in practice as well as gain a better understanding of which of the specific components of collaborative goal setting may be falling short. It is the ability to elucidate these missing components that is critical to our ability to facilitate the use of CGS in practice.

There are a number of strengths and limitations associated with this study. Our primary aim with this study was to identify a set of patient-reported items that could be used to accurately measure the construct of collaborative goal setting. Having done so, this now provides an opportunity to investigate how to reduce the number of items included and thus, the feasibility of using such a measure to routinely assess the quality of patient engagement in diabetes care. Previous studies have illustrated the utility and practicality of using shorter instruments to reduce participant burden. ${ }^{22}$

One of the limitations is that the sample was limited to survey respondents receiving care from VCU-HS. As such, study participants may not be reflective of populations in other healthcare settings or those not responding to the survey. Another limitation is the relatively small sample size for the development of a measure. While there was a high response rate, only 192 respondents $(74 \%)$ reported engaging in a goal-oriented discussion. A priori power estimates suggested a minimum of 200 respondents. Thus, non-significant findings may be due to insufficient power. Even with a small sample size, the effect sizes indicated that the PM-CGS was a highly reliable measure of collaborative goal setting. However, while we were able to uncover robust findings regarding the external validity of the collaborative goal- setting measure, power may have precluded the detection of other important relationships. 
Finally, while the conceptual framework on which survey items were developed highlights the importance of collaborative goal setting occurring over time, the crosssectional survey design precluded exploration of this dimension of collaborative goal setting. On the other hand, strengths of the study include the use of a diverse and random patient sample for which we were able to achieve a relatively high response rate to a mailed survey.

Maximum likelihood is often a preferred estimator for items with a 5-ordered category response format especially when item response distribution is symmetrical. Ideally, an asymptotically distribution-free estimator (eg, diagonally weighted least squares) is appropriate when $\mathrm{N}$ is large and item distributions are non-symmetrical. In this study, we presented a relatively small $\mathrm{N}$ and nonsymmetrical item distributions and opted for maximum likelihood estimator. Studies with large $\mathrm{N}$ will be needed to replicate our results using an asymptotically distribution-free estimator in future studies.

We have shown that a patient-reported instrument can be used to measure collaborative goal setting between patients and their clinicians. The PM-CGS enables us to determine if collaborative goal setting has occurred, and allows us to identify the specific components that are lacking when it does not occur. The ability to do so is important as patient reports of collaborative goal setting have been repeatedly shown to be associated with improved health outcomes.

Acknowledgements We appreciate the assistance of the research coordinator at University of Florida, Kelsey Salazar, who helped with the finalization of the paper.

Contributors All the named authors contributed substantially to the document, provided input, and approved the final paper.

Funding This work was supported by the Agency for Healthcare Research and Quality, grant number R36 HS22202-01.

Competing interests None declared.

Patient consent Obtained.

Ethics approval Institutional Review Board.

Provenance and peer review Not commissioned; externally peer reviewed.

Data sharing statement No additional data are available.

Open Access This is an Open Access article distributed in accordance with the Creative Commons Attribution Non Commercial (CC BY-NC 4.0) license, which permits others to distribute, remix, adapt, build upon this work noncommercially, and license their derivative works on different terms, provided the original work is properly cited and the use is non-commercial. See: http:// creativecommons.org/licenses/by-nc/4.0/

\section{REFERENCES}

1. Lafata JE, Morris HL, Dobie E, et al. Patient-reported use of collaborative goal setting and glycemic control among patients with diabetes. Patient Educ Couns 2013;92:94-9.

2. Langford AT, Sawyer DR, Gioimo S, et al. Patient-centered goal setting as a tool to improve diabetes self-management. Diabetes Educ 2007;33:139S-44S.

3. Williams GC, Patrick $\mathrm{H}$, Niemiec $\mathrm{CP}$, et al. Reducing the health risks of diabetes: how self-determination theory may help improve medication adherence and quality of life. Diabetes Educ 2009;35:484-92.

4. Funnell MM, Anderson RM. Empowerment and self-management of diabetes. Clinical Diabetes 2004;22:123-7.

5. Heisler M, Vijan S, Anderson RB, et al. When do patients and their physicians agree on diabetes treatment goals and strategies, and what difference does it make? J Gen Intern Med 2003;18:893-902.

6. Naik AD, Kallen MA, Walder A, et al. Improving hypertension control in diabetes mellitus: the effects of collaborative and proactive health communication. Circ Arrhythm Electrophysiol 2008;117:1361-8.

7. Naik AD, Palmer N, Petersen NJ, et al. Comparative effectiveness of goal setting in diabetes mellitus group clinics: randomized clinical trial. Arch Intern Med 2011;171:453-9.

8. Funnell MM, Brown TL, Childs BP, et al. National standards for diabetes self-management education. Diabetes Care 2008;31(Suppl 1):S97-104.

9. Pignone MP, Ammerman A, Fernandez L, et al. Counseling to promote a healthy diet in adults: a summary of the evidence for the US Preventive Services Task Force. Am J Prev Med 2003;24:75.

10. Glasgow RE, Wagner EH, Schaefer J, et al. Development and validation of the patient assessment of chronic illness care (PACIC). Med Care 2005;43:436-44.

11. Morris HL, Carlyle K, Lafata JE. Adding the patient's voice to our understanding of collaborative goal setting: how do patients with diabetes perceive collaborative goal setting? Chronic IIIn 2016;12:261-71.

12. How to conduct a cognitive interview: a nutrition education example [article online]. 2005. http://www.au.af.mil/au/awc/awcgate/usda/cog_ interview.pdf (accessed 10 Mar 2014).

13. Jobe JB, Mingay DJ. Cognitive research improves questionnaires. Am J Public Health 1989;79:1053-5.

14. Fowler FJ, Gallagher PM, Stringfellow VL, et al. Using telephone interviews to reduce nonresponse bias to mail surveys of health plan members. Med Care 2002;40:190-200.

15. Cerghet M, Dobie E, Lafata JE, et al. Adherence to disease-modifying agents and association with quality of life among patients with relapsing-remitting multiple sclerosis. International Journal of MS Care 2010;12:51-8.

16. Fowler FJ, Gallagher PM, Nederend S. Comparing telephone and mail responses to the CAHPS (TM) survey instrument. Med Care 1999;37:MS41-9.

17. Williams GC, Freedman ZR, Deci EL. Supporting autonomy to motivate patients with diabetes for glucose control. Diabetes Care 1998;21:1644-51.

18. Anderson LA, Dedrick RF. Development of the trust in physician scale: a measure to assess interpersonal trust in patient-physician relationships. Psychological Rep 1990;67:1091-100.

19. Toobert DJ, Hampson SE, Glasgow RE. The summary of diabetes self-care activities measure: results from 7 studies and a revised scale. Diabetes Care 2000;23:943-50.

20. Kline R. Principles and practice of structural equation modeling New York, NY: The Guilford Press, 2005.

21. Hu LT, Bentler PM. Cutoff criteria for fit indexes in covariance structure analysis: conventional criteria versus new alternatives. Sociol Methods Res 1999;6:1-55.

22. Hibbard JH. Development and testing of a short form of the patient activation measure. Health Serv Res 2005;40:1918-30. 